\title{
La protección de los derechos de las personas con discapacidad en situaciones de crisis: la emergencia sanitaria del COVID-19 en España
}

\section{Protecting the rights of people with disabilities in crisis situations: the COVID-19 health emergency in Spain}

\begin{abstract}
Resumen
Las personas con discapacidad se encuentran entre las más afectadas en situaciones de crisis, debido a múltiples razones. Este trabajo tiene como objeto estudiar la crisis sanitaria del coronavirus en España, a través de los hitos definitorios de la protección de los derechos de este colectivo, analizando la normativa en vigor y toda una serie de documentos relevantes emitidos por diversas instancias autorizadas. El estudio destaca qué aspectos derivados de dicha emergencia afectan especialmente a las personas con discapacidad, cuáles son sus necesidades y la respuesta de los poderes públicos, así como algunas prácticas claramente concultatorias de sus derechos fundamentales. El análisis concluye subrayando la necesidad de que los países firmantes de la Convención sobre los derechos de las personas con discapacidad elaboren protocolos y adopten medidas para garantizar su protección y seguridad, de aplicación rigurosa e inmediata en la gestión de emergencias.
\end{abstract}

\section{Palabras clave}

Personas con discapacidad, derechos humanos, Convención sobre los Derechos de las Personas con Discapacidad, discriminación, gestión de crisis, coronavirus, COVID-19.

\begin{abstract}
People with disabilities are among the most affected in crisis situations, due to multiple reasons. This work aims to study the coronavirus health crisis in Spain, through the defining milestones of the protection of the rights of this group, analyzing the current regulations and a whole series of relevant documents issued by various authorized bodies. The study highlights which aspects derived from said emergency especially affect people with disabilities, what their needs are and the response of the public authorities, as well as some practices that clearly violate their fundamental rights. The analysis concludes by underlining the need for the signatory countries of the United Nations Convention on the Rights of Persons with Disabilities to develop protocols and adopt measures to guarantee their protection and safety, with rigorous and immediate application in emergency management.
\end{abstract}

\section{Keywords}

Persons with disabilities, human rights, Convention on the Rights of Persons with Disabilities, discrimination, crisis management, coronavirus, COVID-19.

\author{
Raquel Valle Escolano \\ $<$ valle.escolano@gmail.com> \\ Confederación Autismo España. \\ España
}

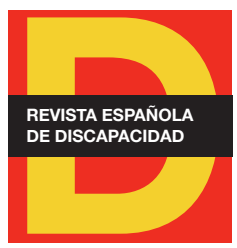

Para citar:

Valle, R. (2020). "La protección de los derechos de las personas con discapacidad en situaciones de crisis: la emergencia sanitaria del COVID-19 en España". Revista Española de Discapacidad, 8(2), pp. 85-106.

Doi: <https://doi.org/10.5569/23405104.08.02.04>

Fecha de recepción: 08-05-2020 Fecha de aceptación: 30-11-2020 


\section{Introducción}

La salud de las personas es un bien jurídico esencial, cuya protección está consagrada en leyes nacionales, normas y tratados internacionales, que al tiempo que proclaman dicho derecho, lo hacen estableciendo que no puede existir ningún tipo de discriminación por razón o circunstancia alguna, personal o social, a la hora de ejercitarlo, ni de los poderes públicos a procurar dicho disfrute igualitario. En el ordenamiento jurídico español son numerosas las normas que contienen ambas ideas, comenzando por la Constitución, que en sus art. 43.1 y 2 reconoce el derecho a la protección de la salud, atribuyendo a los poderes públicos la organización y tutela de la salud pública a través de medidas preventivas y de las prestaciones y servicios necesarios, al tiempo que en su art. 14 sanciona la igualdad ante la ley de todas las personas, prohibiendo cualquier tipo de discriminación, cualquiera que sea su base.

Ambos conceptos aparecen oportunamente combinados en el Real Decreto Legislativo 1/2013, de 29 de noviembre, por el que se aprueba el Texto Refundido de la Ley General de derechos de las personas con discapacidad y de su inclusión social, que proclama el derecho a la igualdad, que las administraciones públicas deben proteger de forma especialmente intensa en el ámbito de la salud, concretándolo en la rotunda afirmación de que las personas con discapacidad tienen derecho a la protección de la salud, incluyendo la prevención de la enfermedad y la protección, promoción y recuperación de la salud, sin discriminación por motivo o por razón de discapacidad, prestando especial atención a la salud mental. También la Ley 14/1986, de 25 de abril, General de Sanidad, reconoce el derecho de las personas con discapacidad a la salud y a todos los derechos que dicha norma establece. Entre ellos, el derecho al respeto a su personalidad, dignidad humana e intimidad, sin discriminación por discapacidad; o a recibir la información sobre los servicios sanitarios en formatos adecuados, siguiendo el principio de diseño para todos, en un modo accesible y comprensible a las personas con discapacidad.

De manera específica, resultan claves los mandatos que nuestro país, tras haber ratificado la Convención sobre los derechos de las personas con discapacidad y su protocolo facultativo, asumió en esta materia desde su entrada en vigor en 2008. Con carácter general, su art. 4 recoge el compromiso de los Estados de asegurar y promover el pleno ejercicio de todos los derechos humanos y las libertades fundamentales de las personas con discapacidad, sin discriminación alguna por motivos de discapacidad, teniendo en cuenta la protección y promoción de los derechos humanos de este colectivo en todas las políticas y programas. También el art. 5 insiste en la idea de que todas las personas son iguales ante la ley, por lo que son acreedoras del derecho a igual protección legal y a beneficiarse de la ley en igual medida, sin discriminación alguna. De forma monográfica, el texto de la citada Convención se refiere en su art. 10 al derecho a la vida de todos los seres humanos, cuyo goce efectivo en igualdad de condiciones por las personas con discapacidad deben garantizar los Estados partes. Una previsión concreta para situaciones de riesgo y emergencias humanitarias se contiene en el art. 11, en virtud de la cual se conmina a los Estados Partes a adoptar, en virtud de las responsabilidades que les corresponden con arreglo al derecho internacional humanitario y el derecho internacional de los derechos humanos, todas las medidas necesarias para garantizar la seguridad y la protección de las personas con discapacidad en situaciones de riesgo, incluidas situaciones de conflicto armado, emergencias humanitarias y desastres naturales. Por su parte, el art. 25 reconoce a este colectivo su derecho a gozar del más alto nivel posible de salud sin discriminación por motivos de discapacidad, que en particular se hará efectivo mediante la exigencia a los y las profesionales de la salud de que presten a las 
personas con discapacidad atención de la misma calidad que al resto, poniendo en valor la sensibilización respecto de los derechos humanos, la dignidad, la autonomía y las necesidades de las personas con discapacidad a través de la capacitación y la promulgación de normas éticas para la atención de la salud en los ámbitos público y privado. En este mismo artículo se establece que los Estados partes impedirán que se nieguen, de manera discriminatoria, servicios de salud o de atención de la salud o alimentos sólidos o líquidos por motivos de discapacidad.

La ratificación de la Convención trajo consigo la Ley 26/2011, de 1 de agosto, y el Real Decreto 1276/2011, de 16 de septiembre, ambos de adaptación normativa a la Convención Internacional sobre los derechos de las personas con discapacidad, con el objetivo de adecuar la regulación afectada a las directrices marcadas por la misma, modificando para ello 28 normas. En particular, la citada Ley declara en su preámbulo su decidido impulso reformador en el sentido de salvaguardar los derechos de las personas con discapacidad, con el objetivo de favorecer la toma de decisiones en todos los aspectos de su vida, tanto personal como colectiva, avanzar hacia la autonomía personal desinstitucionalizada y garantizar la no discriminación en una sociedad plenamente inclusiva; y con ello subraya el cambio de paradigma en el ordenamiento español hacia un enfoque que considera a las personas con discapacidad como sujetos titulares de derechos y no como meros objetos de tratamiento y protección social.

Desde la óptica comunitaria, destacan también normas como la Carta Social Europea de 1961, ratificada en 1980 y revisada en 1996, que consagra claros derechos para las personas con discapacidad en materia de educación, formación, empleo, participación y salud, estableciendo la garantía de que todos los derechos establecidos en la Carta serán aplicables sin discriminación alguna a todas las personas. En la misma línea, la Estrategia Europea sobre Discapacidad 2010-2020 (Unión Europea, 2010) constituye un compromiso renovado para una Europa sin barreras, y proporciona un marco de acción a escala europea y nacional, para avanzar en los derechos de las personas con discapacidad en ámbitos primordiales de actuación: accesibilidad, participación, igualdad, empleo, educación y formación, protección social, sanidad y acción exterior.

El mensaje de todas estas normas está claro: las personas con discapacidad tienen en nuestro país idéntico derecho al del resto, a disfrutar de su derecho a la salud, y a ser protegidas por los poderes públicos en igual grado, teniendo en cuenta sus peculiares necesidades. No puede obviarse, sin embargo, que pese a la rotundidad con que estas normas consagran sus derechos, y reconociendo los avances habidos en España en las últimas décadas, las personas con discapacidad sufren en el día a día una discriminación estructural que se refleja en múltiples aspectos y terrenos, y cuyo resultado acumulativo no es otro que el restarles igualdad de oportunidades y depreciar su calidad de vida. Y si ello ocurre en situaciones ordinarias, la inequidad crece exponencialmente en cualquier contexto de crisis.

\section{Marco teórico}

La revisión de la literatura académica en este ámbito nos ofrece estudios diversos, realizados a partir de situaciones de existencia o incremento de dificultades, en definitiva, de crisis, que, por supuesto, difieren en sus causas en los países desarrollados y en los países en desarrollo, ya que estos últimos padecen conflictos y 
problemas que no se dan en los primeros, y los encaran con medios muchísimo más precarios. No obstante, si hay un denominador común entre ambos es el hecho de que las personas con discapacidad ven acentuada exponencialmente su situación de vulnerabilidad, y si la sociedad y los poderes públicos en situaciones ordinarias en ocasiones ignoran sus demandas y desatienden sus derechos, en circunstancias extraordinarias de crisis olvidan sus necesidades, dejando de desarrollar las políticas públicas y de tomar las medidas necesarias para posibilitar la igualdad de oportunidades y la equidad en el ejercicio de los derechos.

Muchos de estos estudios abordan los efectos de las diversas crisis económicas y las políticas de austeridad sobre la población con discapacidad, documentando el impacto diferencial que tales circunstancias tienen restringiendo aspectos como la atención a sus necesidades en materia de salud (Rotarou y Sakellariou, 2017), o limitando sus derechos laborales, en términos de inserción laboral y salarios (Hernández y Millán, 2015).

En otro orden de cosas, también se han estudiado fenómenos de crisis migratoria, concluyendo que las personas migrantes con discapacidad son una población oculta, cuyas experiencias a menudo se pasan por alto o se subsumen en debates más amplios (Burns, 2017).

Con un carácter más general, presenta interés el trabajo de Mitchell y Karr (2014), que constata que las personas con discapacidad están sujetas a discriminación severa y son a menudo ignoradas en situaciones de crisis y conflicto. Aborda cómo satisfacer sus necesidades en tales situaciones, haciendo referencia a normas, políticas y estrategias a implementar; detalla los riesgos a que están expuestos; y hace referencia a programas y buenas prácticas, exponiendo al tiempo modos de participación de las personas con discapacidad en los procesos de reconstrucción.

En una línea similar, una consulta global realizada en 2015 en el terreno de la actuación de las organizaciones humanitarias (Handicap International Federation) determinó que las personas con discapacidad se ven fuertemente afectadas en situaciones de crisis, constatando impacto físico directo, abuso psicológico, físico o sexual, estrés psicológico y/ o desorientación. También sufren mayores dificultades para acceder a la ayuda humanitaria básica, lo que se une a la escasa o nula disponibilidad de los servicios específicos, muchos de ellos esenciales, que requieren las personas con discapacidad, como rehabilitación, dispositivos de asistencia, acceso a trabajadores sociales o intérpretes. Las principales barreras que les afectan tienen que ver con la falta de información accesible sobre los servicios disponibles, así como con la propia dificultad para llegar a los mismos, debido ya a una falta de acceso físico o financiero, a la inexistencia de personal de apoyo capacitado en materia de discapacidad, o a la distancia a la que tales servicios se prestan. El estudio subraya la mayor vulnerabilidad de las personas con discapacidad en tiempos de crisis, que no se ve respaldada por una asistencia verdaderamente inclusiva. Pese a algunos avances constatados en este terreno, existen todavía desafíos pendientes de gran envergadura, como la necesidad de identificación de personas con discapacidad, de evaluación inicial de sus necesidades, la insuficiente consulta a los mismos, la falta de experiencia técnica en discapacidad, obstáculos financieros, prestación de servicios no accesibles, falta de sensibilización de los actores humanitarios y de la población en general e insuficiente coordinación entre actores. Se requieren, por tanto, cambios en las políticas y prácticas en la gestión humanitaria de las crisis.

En este contexto de escenarios de dificultad o alerta extraordinarias, es precisamente en el que se sitúa la crisis del COVID-19. El 31 de diciembre de 2019, la Comisión Municipal de Salud y Sanidad de Wuhan (China) dio cuenta de 27 casos de neumonía de etiología desconocida. Las autoridades chinas identificaron 
en enero de 2020 a un virus de la familia Coronaviridae (el SARS-CoV-2) como agente causante, y el cuadro clínico asociado al mismo se ha denominado COVID-19 (coronavirus disease 2019). El día 11 de marzo se había expandido por más de cien países, lo que llevó a la OMS a la declaración de pandemia mundial.

Hasta el momento, no existe más que un tratamiento sintomático y de apoyo contra el virus por lo que, dado el importante número de afectados a nivel mundial y con objeto de frenar y prevenir su expansión, los diversos gobiernos han impuesto un conjunto de medidas, que incluyen restricción de viajes y de movilidad de la ciudadanía, cierre de colegios, empresas y universidades, confinamiento en los hogares, aislamiento social, clausura de establecimientos y cancelación de eventos. La casi totalidad de actividades sociales y económicas se han visto afectadas, reduciéndose al mínimo la actividad y el funcionamiento ordinario de los países, donde todos los esfuerzos se dirigen al ámbito sanitario y a los sectores esenciales para la vida diaria o directamente relacionados con la prevención y la sanidad. La pandemia está teniendo un grave impacto socieconómico, y sin duda traerá consecuencias todavía impredecibles.

\section{Objetivos y metodología}

Este trabajo analiza cuáles han sido los efectos de la pandemia ocasionada por el coronavirus sobre las personas con discapacidad, medido a través del respeto a sus derechos, consagrados en la Convención y resto de normativa aplicable. En particular, el análisis pretende conocer:

- La reacción de los poderes públicos, y si las diversas medidas tomadas contemplaron a las personas con discapacidad.

- La cobertura de sus necesidades durante la crisis, en los diversos ámbitos.

- La eventual existencia de vulneraciones de derechos humanos.

- La respuesta de la sociedad civil, de las personas con discapacidad y sus familias, articulada a través de sus organizaciones representativas.

En definitiva, se trata de evaluar la vigencia de los derechos de las personas con discapacidad, que el ordenamiento jurídico español consagra rotundamente, en una época de crisis, como la generada en la actual pandemia, a través del análisis de las cuestiones mencionadas.

El hecho de que la crisis no haya finalizado no impide estudiar los aspectos anteriores, que ya han quedado patentes en el diseño de la gestión de la crisis, cuyo engranaje, líneas de acción y medidas esenciales están en marcha, habiéndose producido además posicionamientos por parte de todos los actores sociales afectados por el proceso. El estudio se realizó en abril de 2020, aunque de forma previa a su publicación incluyó aspectos contemplados en documentos posteriores.

El trabajo se basa en el análisis sistemático de numerosa documentación relativa al modo en que la crisis del COVID-19 afecta a las personas con discapacidad, que dé respuesta a los objetivos que se plantea este estudio. Ello incluye una importante selección de documentos, de tipología diversa: 
- En primer lugar, una serie de comunicados institucionales de diferentes autoridades, como el Gobierno español, la Organización Mundial de la Salud -OMS - , la Comisión Europea y otros órganos comunitarios, a través de los cuales, en los diversos ámbitos, se diseñan estrategias y se ponen en marcha pautas concretas con objeto de gestionar la crisis del COVID-191. Dichas normas y comunicados identifican objetivos, imparten instrucciones de cumplimiento preceptivo para la ciudadanía, implementan medidas y realizan recomendaciones diversas para mitigar los efectos más preocupantes de la crisis, con la finalidad controlar la situación. En este grupo, y en la medida en que se trata de una crisis sanitaria, se considerarán asimismo las instrucciones y/o las recomendaciones realizadas desde instancias oficiales o desde sociedades médicas, que puedan afectar a las personas con discapacidad.

- En segundo lugar, se analizará un conjunto de documentación cuya autoría corresponde a diversos entes y organizaciones, ya españolas (Comité Español de Representantes de Personas con Discapacidad -CERMI - , Confederación Autismo España); o de ámbito internacional (OMS, International Disability Alliance ${ }^{2}-$ IDA - , órganos y comités diversos de la ONU), que representan a las personas con discapacidad $^{3}$. Se trata de manifestaciones en las que estos actores han ido poniendo de manifiesto las necesidades de dicho colectivo en este periodo de crisis, realizando interesantes recomendaciones en numerosos ámbitos. También han subrayado las carencias de las actuaciones desarrolladas, los ámbitos a reforzar desde los poderes públicos, e incluso han denunciado recomendaciones y/o prácticas que contenían flagrantes violaciones de los derechos de las personas con discapacidad.

- Finalmente, un tercer grupo de pronunciamientos abordados en este estudio se centran en los aspectos éticos de la pandemia, en un contexto de grave escasez de recursos sanitarios, sobre cuyo uso y planificación se han realizado recomendaciones por parte de sociedades médicas y otras instancias. En este debate se analizan documentos elaborados por académicos, comités éticos u otras instancias esenciales en materia de protección de derechos humanos, como el Defensor del pueblo español, e incluso desde el propio Ministerio de Sanidad ${ }^{4}$. Todos ellos tienen en común el realizar un discurso que subraya las implicaciones éticas de algunas de las recomendaciones realizadas y medidas concretas adoptadas en el curso de la crisis sanitaria.

\footnotetext{
1. En esta categoría figuran documentos como el Real Decreto 463/2020, por el que se declara el estado de alarma para la gestión de la situación de crisis sanitaria ocasionada por el COVID-19; el Real Decreto 465/2020, por el que se modifica el Real Decreto 463/2020, por el que se declara el estado de alarma; el Real Decreto-Ley 8/2020, de medidas urgentes extraordinarias para hacer frente al impacto económico y social del COVID-19; la Instrucción de 19 de marzo de 2020, del Ministerio de Sanidad, por la que se establecen criterios interpretativos para la gestión de la situación de crisis sanitaria ocasionada por el COVID-19; la documentación en diversos órdenes que, bajo el título Información Coronavirus, mantenía y actualizaba el Ministerio de Sanidad; Presidency Report on the state of play of EU-coordination in response to the COVID-19 pandemic; o la Alocución de apertura del Director General de la OMS en la rueda de prensa sobre la COVID-19, de 11 de marzo de 2020.

2. International Disability Alliance es una alianza de redes mundiales y regionales, que reúne a más de 1100 organizaciones de personas con discapacidad y sus familias, y se dedica a promover sus derechos, abogando ante sus gobiernos por cambios a nivel local, nacional e internacional. 3. Se han analizado los siguientes documentos: el emitido por el CERMI, Las personas con discapacidad y sus familias ante la crisis sanitaria del coronavirus: prontuario de necesidades en la gestión inmediata de la pandemia; la Declaración conjunta representantes ONU: Personas con discapacidad y COVID-19, efectuada por el Presidente del Comité de Derechos de las Personas con Discapacidad de las Naciones Unidas, y la Enviada Especial del Secretario General de las Naciones Unidas sobre Discapacidad y Accesibilidad; Toward a Disability-Inclusive COVID19 Response: 10 recommendations from the International Disability Alliance; la Declaración del Comité de Derechos del Niño de las Naciones Unidas, de 8 de abril de 2020; Disability considerations during the COVID-19 outbreak, de la Organización Mundial de la Salud; alertas de la ONU, plasmadas en textos como ¿Quién protege a las personas con discapacidad?; el Mensaje del Secretario General de la ONU con motivo del Día Mundial de Concienciación sobre el Autismo, de 2 de abril de 2020; ○ ¿Qué puede ocurrirle a la persona con trastorno del espectro del autismo que se ve afectada por las medidas establecidas en el RD463/2020, de 14 de marzo?, documento elaborado por la Confederación Autismo España.

4. Entre estos documentos, las Recomendaciones éticas para la toma de decisiones en la situación excepcional de crisis por pandemia covid-19 en las unidades de cuidados intensivos, de la Sociedad Española de Medicina Intensiva, Crítica y Unidades Coronarias (SEMICYUC); el Informe del Ministerio de Sanidad sobre los aspectos éticos en situaciones de pandemia: el SARS-CoV-2; el Documento de posicionamiento Derecho a la salud de las personas con trastorno del espectro del autismo, en la situación de crisis sanitaria por COVID-19, de la Confederación Autismo España; el Informe del Comité de Bioética de España sobre los aspectos bioéticos de la priorización de recursos sanitarios en el contexto de la crisis del coronavirus; el Documento del Defensor del Pueblo de 27/3/2020; o el documento de De Asís, Ética y derechos humanos: sobre las recomendaciones éticas para la toma de decisiones en la pandemia COVID-19.
} 


\section{Resultados}

El estudio del conjunto de documentos mencionados permite llegar a los siguientes resultados, en los siguientes órdenes de cuestiones:

1. Atención específica a las personas con discapacidad en las medidas institucionales iniciales de gestión de la crisis del Covid 19. Toma en consideración de sus solicitudes y sugerencias.

2. Necesidades concretas de las personas con discapacidad y aspectos de su vida diaria potencialmente afectados por la pandemia.

3. El papel de las organizaciones representativas de las personas con discapacidad en una gestión inclusiva de la crisis del Covid 19.

4. Consideraciones éticas de la pandemia, en relación con las personas con discapacidad.

\section{Atención específica a las personas con discapacidad en las medidas institucionales iniciales de} gestión de la crisis del Covid 19. Toma en consideración de las solicitudes y sugerencias realizadas

La extensión del virus, el agravamiento de sus consecuencias y la consiguiente declaración de la pandemia mundial por la OMS, provocaron la puesta en marcha una serie de medidas institucionales por parte de las autoridades de los diversos países. En España, la primera de ellas fue la declaración del estado de alarma, inicialmente por 15 días, para todo el territorio nacional, para la gestión de la crisis sanitaria ocasionada por el COVID-19, a través del Real Decreto 463/2020, de 14 de marzo. Esta norma estableció medidas de carácter extraordinario para prevenir y contener el virus y mitigar el impacto sanitario, social y económico mediante previsiones reguladoras y limitativas; entre ellas, medidas de contención en el ámbito de la actividad comercial, equipamientos culturales, establecimientos recreativos, actividades de hostelería y restauración, así como en el ámbito educativo y de formación, para el aseguramiento del suministro de bienes y servicios necesarios para la salud pública, transportes, abastecimiento alimentario, suministro de energía eléctrica y gas natural, o en materia de comunicación.

Destacan entre todas ellas, en relación con los derechos de la ciudadanía, las previsiones tendentes a limitar la libertad de circulación, ya que el Real Decreto establece que las personas únicamente podrán circular por las vías de uso público para la realización de una lista cerrada de actividades (adquisición de alimentos, productos farmacéuticos y de primera necesidad; asistencia a centros y establecimientos sanitarios; desplazamiento al lugar de trabajo para efectuar su prestación laboral, profesional o empresarial; a entidades financieras y de seguros; por causa de fuerza mayor...). Entre tales circunstancias que permiten salir y desplazarse, se encuentra la asistencia y cuidado a mayores, menores, dependientes, personas con discapacidad o personas especialmente vulnerables. También se permite salir para cualquier otra actividad de análoga naturaleza, lo que habrá de hacerse individualmente, salvo que se acompañe a personas con discapacidad o por otra causa justificada.

Las previsiones citadas fueron las únicas que contemplaban de forma específica a las personas con discapacidad, permitiendo a sus cuidadores la circulación para continuar garantizando su asistencia. No se pensó, sin embargo, en que el confinamiento total de estas personas, aun basándose en estrictos motivos de 
salud pública, podría ser muy problemático o casi inviable para determinadas tipologías de discapacidad, lo que provocó una reacción de las entidades representativas de dichos colectivos, poniendo de manifiesto sus necesidades. Tampoco se les mencionó, estableciendo alguna disposición general que pusiera de manifiesto su especial vulnerabilidad, sensibilizando a la población y a los actores especialmente relevantes en el estado de alarma, como profesionales sanitarios, o fuerzas y cuerpos de seguridad, encargados de hacer cumplir las previsiones legales extraordinarias.

Seis días después de la aparición del Real Decreto inicial, se publicaba en el BOE la Instrucción de 19 de marzo de 2020, del Ministerio de Sanidad, por la que se establecen criterios interpretativos para la gestión de la situación de crisis, que permitía a las personas con discapacidad con alteraciones conductuales, como por ejemplo personas con diagnóstico de espectro autista y conductas disruptivas, que se pudiera ver agravado por la situación de confinamiento derivada de la declaración del estado de alarma, y a un acompañante, circular por las vías de uso público, siempre y cuando se respetaran las medidas necesarias para evitar el contagio.

El análisis de estas medidas iniciales pone claramente de manifiesto, en línea con lo que subraya el CERMI (2020a), el escaso conocimiento e implantación de la Convención y de los mandatos de derechos humanos en las políticas públicas españolas. A día de hoy, no ha calado en la sociedad española dicho enfoque, basado en la dignidad y la autodeterminación, lo que se evidencia en la falta de previsiones relativas a las personas con discapacidad en las primeras normativas aparecidas en la pandemia.

\section{Necesidades concretas de las personas con discapacidad y aspectos de su vida diaria potencialmente afectados por la pandemia}

Una de las características de esta crisis de salud pública y de las disposiciones adoptadas para combatirla es el hecho de que estas últimas afectan a numerosos ámbitos (al estrictamente personal, al social, al económico...), y lo han hecho de una forma casi inmediata, prácticamente sin dar tiempo a planificar y organizar la atención a muchas necesidades esenciales para las personas. Ello adquiere mayor relevancia cuando hablamos de las personas con discapacidad, mucho más vulnerables que el resto y, por tanto, necesitadas de apoyos y medidas que se han visto profundamente afectadas por el estado de alarma decretado en España.

Las necesidades específicas de las personas con discapacidad en esta crisis han sido puestas de manifiesto en numerosos documentos, elaborados por organizaciones que representan a dicho colectivo, que tratan de sensibilizar y apuntar dichos requerimientos, esenciales y olvidados o ni siquiera advertidos por las autoridades y la ciudadanía. Su análisis nos permite sistematizar cuáles son tales necesidades y, a partir de las mismas, qué indicaciones se formulan a los poderes públicos, exhortándoles a adoptar medidas específicas, planificadas y dirigidas a responder adecuadamente a la problemática que la pandemia puede causar en las personas con discapacidad (que es en algunos casos particular y que en general resulta mucho más agravada por su vulnerabilidad), asegurando su efectiva inclusión y la participación efectiva de familias y de sus entidades representativas en la gestión de esta crisis.

Las recomendaciones abarcan un amplio catálogo, en los diferentes órdenes de cuestiones: 


\section{a. Información y servicios accesibles}

Toda la información pública relacionada con la crisis del COVID-19 debe ser accesible para las personas con discapacidad, de modo que puedan obtenerla en igualdad de condiciones con los demás; una accesibilidad que debe ser universal, esto es, susceptible de llegar a todos los miembros de este colectivo sin excepciones. Esta previsión debe alcanzar a todos los servicios disponibles en todas las esferas, tales como comparecencias de autoridades, consejos para controlar la infección, planes de restricción pública, instalaciones de cuarentena, incluida la información sobre suministros y servicios esenciales, o los servicios remotos para trabajadores y estudiantes con discapacidad; en definitiva, a todas las prestaciones e información relevantes. La accesibilidad es predicable de todas las plataformas, medios, canales y formatos de comunicación, y se concreta a través de prestaciones y servicios como sistemas telefónicos y telemáticos de atención y asesoramiento; subtitulado, lengua de signos, audiodescripción, alto contraste, caracteres ampliados; medidas de accesibilidad cognitiva como lectura fácil, pictogramas; intérpretes de lengua de signos y mediadores comunicativos, etc.

b. Medidas de protección adicionales, que respondan a los mayores riesgos de contraer el coronavirus $u$ otras enfermedades

Deben tomarse medidas de protección adicionales para las personas con ciertos tipos de discapacidad, por su mayor fragilidad y vulnerabilidad, debida, entre otros factores, a las barreras de acceso a la información preventiva y a la higiene, a la dependencia del contacto físico con su entorno y con las personas de apoyo, así como a afecciones respiratorias causadas por ciertas tipologías de discapacidad. Dichas medidas serán diversas en función de la discapacidad concreta. Así, por ejemplo, deben extremarse las prevenciones de contagio en los espacios en que se mueven las personas de movilidad reducida. A las personas con discapacidad psicosocial, problemas mentales y con trastornos del desarrollo, el confinamiento y la alteración de sus rutinas pueden generarles miedo y ansiedad, que será necesario contrarrestar, siendo esencial para ello el apoyo comunitario. Finalmente, deberán realizarse las pruebas oportunas y extremar la prevención con ciertos grupos de personas más vulnerables a infecciones respiratorias o de otra índole causadas o asociadas con su discapacidad. A todas estas circunstancias deberán dar los poderes públicos una adecuada respuesta en la gestión de la pandemia.

\section{c. Restricciones y personas con discapacidad}

Las medidas que supongan restricciones públicas, tales como el confinamiento, deben considerar a las personas con discapacidad en igualdad de condiciones con los demás, garantizándoles mientras dura su vigencia todos los servicios de apoyo, asistencia personal y accesibilidad, velando por ello por la salud de las y los profesionales que les apoyan, y procurando su autonomía.

Sin embargo, determinadas personas con discapacidad intelectual, psicosocial, del desarrollo, trastorno del espectro del autismo, asperger, enfermedad mental, daño cerebral adquirido, y otras, no pueden, por razones perentorias asociadas a su discapacidad, permanecer confinadas indefinidamente en sus domicilios, y requieren acceder a la vía pública como único modo de evitar episodios de colapso personal que podrían afectar muy negativamente a su salud y bienestar psicofísico y emocional. En tales casos, las medidas públicas deben prever que puedan hacerlo, por razones terapéuticas. 
d. Sensibilización a la sociedad, concienciación y capacitación de los y las profesionales y actores en la crisis

Debe sensibilizarse a la sociedad, de modo que pueda tomar conciencia sobre el apoyo que requieren las personas con discapacidad, integrándolo en todas las campañas de protección. De igual modo, agentes de la autoridad y proveedores de servicios, incluidos los servicios de respuesta a emergencias, deben recibir una rápida capacitación y formación, tanto sobre los derechos de las personas con discapacidad como sobre sus riesgos específicos, asociados con las complicaciones de salud que los exponen más al contagio del coronavirus.

e. Institucionalización cero y garantía de los servicios de apoyo, asistencia personal, accesibilidad universal

Las recomendaciones instan a desinstitucionalizar a las personas con discapacidad de todo tipo de instituciones, tales como hospitales psiquiátricos y otros centros de internamiento, donde existen mayores riesgos para las mismas. Tampoco son admisibles la institucionalización y el abandono basados en la discapacidad en esta crisis sanitaria. Una eventual hospitalización no debe durar más allá del tiempo necesario para superar la etapa de enfermedad y debe realizarse en igualdad de condiciones que para las demás personas.

Las personas con discapacidad y/o en situación de dependencia y sus familias deben seguir siendo atendidas, incluso con mayor intensidad, durante la situación de crisis, ya que la autonomía personal de aquellas, o el desempeño de las actividades básicas de la vida diaria, requieren de la colaboración de terceros. De ahí que los servicios de apoyo, incluido el cuidado de asistencia domiciliaria y personal, resultan esenciales para el ejercicio efectivo de sus derechos, no pudiendo sufrir interrupciones en el periodo de cuarentena. $Y$ caso de que las redes familiares y sociales de apoyo deban ser aislados, requieren ser reemplazados. En todo caso, durante el tiempo que dure la crisis, deben de estar garantizados los servicios de apoyo, asistencia personal, accesibilidad física y comunicación.

\section{f. Atención sanitaria de calidad, en condiciones de igualdad y no discriminación}

El Estado de derecho debe garantizar una atención sanitaria equitativa y sin discriminaciones durante la pandemia, que proteja la vida humana y su dignidad sin excepciones. Las autoridades deben adoptar todas las medidas apropiadas para garantizar el acceso de las personas con discapacidad a los servicios de salud (dado que éstas se enfrentan a barreras adicionales al buscar atención médica), y proporcionarles el mismo nivel y calidad de atención sanitaria que se brinda al resto de personas, evitando la denegación discriminatoria de cualquier tipo de servicio sanitario por razón de discapacidad. Antes bien, las personas con discapacidad que necesitan atención sanitaria por COVID-19, por su mayor fragilidad de salud, deberían ser objeto de tratamiento preferencial. Por ello, los mensajes de comunicación de salud pública deben ser respetuosos y no discriminatorios, y las instrucciones al personal sanitario deben subrayar el igual valor de la dignidad de todas las vidas humanas.

Por otro lado, se deben seguir brindando a las personas con discapacidad los servicios de salud específicamente requeridos por los mismos. Es necesario implementar medidas que garanticen la continuidad en el cuidado y la asistencia médica, así como, en su caso, la prestación de los servicios de rehabilitación durante el periodo de crisis, ya que son esenciales para el ejercicio efectivo de sus derechos. 
g. Enfoque inclusivo; participación y cooperación de las organizaciones y familias de personas con discapacidad en la gestión de la crisis

Los Estados deben garantizar que las personas con discapacidad y sus familias, a través de sus organizaciones representativas, sean consultadas e involucradas activamente en la planificación, implementación y seguimiento de las medidas de gestión de la pandemia.

Este diálogo civil, que dé voz a las organizaciones de personas con discapacidad y canalice su cooperación y asesoramiento, resulta esencial para que todas las medidas que se adopten se configuren desde un enfoque inclusivo, que tenga en cuenta las necesidades y características de estas personas, de modo que se les trate en un plano de igualdad con el resto de la ciudadanía. La inclusión debe abarcar cualquier consideración o medida que se adopte en la gestión de esta crisis.

h. Atención específica a determinados colectivos de personas con discapacidad, acreedores de protección adicional

Los Estados deben asimismo considerar la diversidad entre las personas con discapacidad, incidiendo a través de un enfoque particular en el género y la edad, así como en la situación de los miembros de este grupo de población que se enfrentan a mayores dificultades. Por ello, en las recomendaciones realizadas se realizan llamamientos a atender situaciones de pobreza y privación de las personas con discapacidad en los diversos planes de gestión de crisis, instando a abordar las eventuales dificultades económicas de este colectivo, derivadas de la pérdida de empleos y de sus barreras adicionales para satisfacer las necesidades básicas esenciales.

A partir de consideraciones de género, se insta a tener especial atención con las madres y cuidadoras, para que esta emergencia no impacte de forma desmedida en las mujeres, para lo que se recomienda incluir la perspectiva de género en cualesquiera programas y acciones, así como prevenir la violencia y abusos sobre niñas y mujeres con discapacidad, al existir evidencias de que tales situaciones se incrementan en situaciones de crisis extraordinarias.

\section{i. Protección especial de los niños y niñas con discapacidad}

La vulnerabilidad de los niños y niñas con discapacidad se incrementa aún más por las excepcionales circunstancias causadas por la pandemia. El Comité de los Derechos del Niño de Naciones Unidas (ONU, 2020c) advierte del grave impacto físico, emocional y psicológico del COVID en la infancia y pide a los Estados que tomen medidas, recomendando que las restricciones sean proporcionales, mínimas y limitadas en el tiempo, y se contemple al menos una salida al día al exterior, respetando las medidas de distancia social y supervisadas; desinstitucionalización de menores; que la educación online no aumente las desigualdades de personas con limitaciones; atención médica y protección, incluidas las visitas a domicilio, con servicios profesionales de salud mental para niños y niñas en confinamiento; así como brindar oportunidades para que sus opiniones sean escuchadas y tomadas en cuenta.

El análisis de las medidas adoptadas en España, en relación con los derechos de las personas con discapacidad consagrados en la Convención y resto de normativa, relacionados en la introducción de este trabajo, y reflejados en las recomendaciones anteriores en los diferentes ámbitos, permite concluir que tales derechos han sido claramente vulnerados. 
Dicha situación, lamentablemente, es común a muchos otros países. En este sentido, un informe de la Asociación europea de proveedores de servicios a las personas con discapacidad (Bignal y GouvierSeghrouchni, 2020), realizado a partir de datos de 23 países europeos, confirma la absoluta falta de previsión y directrices en relación con los servicios que este grupo de población precisa para vivir en igualdad de condiciones con el resto de la ciudadanía, con dignidad y autonomía. Se constatan además aspectos como la falta de equipos para el personal que los acompaña, la disminución de servicios presenciales y su sustitución por otros online, menos satisfactorios, y la preocupación por la caída del empleo de las personas con discapacidad. Por su parte, un estudio de CEPAL (2020) en los países de América Latina y el Caribe, subraya como el mayor problema la asociación entre discapacidad y pobreza, e informa de que las personas con discapacidad van a ver incrementado su desempleo; tienen problemas con la escolarización; y que el confinamiento físico puede interrumpir su acceso a bienes y servicios esenciales que precisan para mantener su bienestar. Por ello, insta a respetar los derechos fundamentales e inalienables de todas las personas en el contexto de la crisis y en el período de recuperación, independientemente de su situación de discapacidad, y a atender en particular a grupos en especial situación de desventaja, como mujeres, niños, niñas y adolescentes con discapacidad, velando por que las medidas tomadas para afrontar la crisis y durante el período de recuperación, ya sanitarias o sobre protección del empleo y continuidad educativa, incorporen la perspectiva de discapacidad.

\section{El papel de las organizaciones representativas de las personas con discapacidad en una gestión inclusiva de la crisis del COVID-19}

A diferencia de las previsiones de las diversas instancias ejecutivas, que no han demostrado una gran sensibilidad a la hora de considerar el modo en que la crisis podía afectar a las personas con discapacidad e integrar sus requerimientos en las disposiciones y medidas adoptadas, el análisis de las reacciones de las organizaciones representativas del colectivo permite concluir que las mismas han sido rápidas, han recogido de forma sistemática las carencias registradas en relación a sus necesidades, y han procurado que sus reivindicaciones y denuncias tuvieran la oportuna difusión. En este sentido, ya se han mencionado los posicionamientos y continuas recomendaciones efectuadas por instancias representativas de las personas con discapacidad y/o competentes en la materia. Entre ellas se encuentran, a nivel nacional, el CERMI o la Confederación Autismo España, mientras que en el ámbito internacional lo han hecho la OMS, International Disability Alliance, o diversos órganos de las Naciones Unidas (el Comité de Derechos de las Personas con Discapacidad o la Relatora Especial para sus derechos).

El papel de estas organizaciones y entidades no es otro que representar a las personas con discapacidad y defender sus derechos, por lo que su actuación en esta pandemia, reivindicando atención, sensibilización y un tratamiento inclusivo e igualitario, entra dentro de sus cometidos. Sin embargo, hay que subrayar que han reaccionado con celeridad y han elaborado decálogos que tienen en cuenta los diferentes aspectos que pueden afectar a las personas con discapacidad, abogando por respuestas a la crisis que consideren de una forma inclusiva a este sector de la población.

Su papel se ha demostrado esencial, y debieran jugar un rol clave, en la medida en que tales organizaciones pueden actuar proactivamente, llegando a todos los poderes públicos y autoridades, no solo sanitarias, sino también educativas o competentes en otros terrenos, así como a los medios de comunicación. Su conoci- 
miento sobre el modo en que la pandemia y las medidas de respuesta pueden afectar de forma diferencial a las personas con discapacidad es claramente valioso, como lo es su asesoramiento en el diseño de estrategias para derribar barreras y atajar las problemáticas con que se enfrentan las personas con discapacidad, implantando medidas que favorezcan su desarrollo y posibiliten el ejercicio de sus derechos en condiciones de igualdad. Finalmente, las organizaciones representativas de las personas con discapacidad y sus familias pueden ser actores esenciales, en orden a sensibilizar y concienciar en torno a la discriminación estructural que este sector de la población sufre, y singularmente hacerlo en crisis como la actual, en la que toda la ciudadanía requiere de un claro apoyo público, y en particular las personas con discapacidad.

\section{Consideraciones éticas de la pandemia, en relación con las personas con discapacidad.}

Uno de los riesgos más acusados de la crisis del COVID-19, lo constituye la escasez de recursos y de atención sanitaria para hacer frente a las necesidades de las personas infectadas por el virus. Los recursos disponibles, ya sea de profesionales sanitarios, equipamientos, instalaciones médicas, hospitales y unidades de cuidados intensivos, han sido claramente insuficientes para la atención clínica requerida. Procurar mitigar dicho desequilibro temporal, ha sido una de las causas principales del confinamiento de la población.

En dicho contexto, se han emitido diferentes manifiestos con instrucciones y recomendaciones por parte de sociedades médicas y otras instancias, sobre cómo administrar unos recursos sanitarios que son escasos. Ante los mismos, ha habido posicionamientos oficiales, así como reacciones de instancias diversas; a continuación, haremos referencia a las más relevantes.

a) En nuestro país destaca, por la repercusión que ha alcanzado, el documento del Grupo de Trabajo de Bioética de la Sociedad Española de Medicina Intensiva, Crítica y Unidades Coronarias (SEMICYUC), de Recomendaciones éticas para la toma de decisiones en la situación excepcional de crisis por pandemia Covid-19 en las unidades de cuidados intensivos.

El discurso tiene como eje lo que denomina principios de justicia distributiva y maximización del beneficio global, y establece la necesidad de aplicar en esta situación excepcional sistemas de triaje y atención a las necesidades de ventilación mecánica, y en general de asignación de recursos, que prioricen el máximo beneficio de todos los pacientes frente a su orden de llegada. El documento es extenso y establece, entre otras cuestiones, diversos grupos de prioridad en el triaje para el ingreso en UCIS.

Un gran número de estas recomendaciones resultan absolutamente contrarias a la Convención, en la medida en que manejan criterios puramente utilitaristas, sin considerar el valor de las personas y sus vidas como bienes jurídicos únicos, no matizables ni susceptibles de inclusión en diversas categorías, teniendo en cuenta un pretendido beneficio cuantificable que obtiene la sociedad en su conjunto, de que una persona viva o deje de hacerlo. En este sentido, valora como de segunda a personas de edad, ya afectadas por otras dolencias, o que no tengan a otros individuos a su cargo. En esta línea destacan las siguientes recomendaciones:

- En personas mayores se debe tener en cuenta la supervivencia libre de discapacidad por encima de la supervivencia aislada. 
- Tener en cuenta el valor social de la persona enferma.

El documento establece sin tapujos que pretende maximizar el bien común, y lo hace ordenando a las personas en función de un pretendido valor social, un concepto altamente discriminatorio, que sacrifica bienes jurídicos y derechos esenciales ligados a las personas, cuyo valor surge del hecho de serlo y no de lo que supuestamente la sociedad puede extraer como beneficio de las mismas, teniendo en cuenta criterios altamente discutibles y antitéticos a los derechos humanos. El derecho a la vida, a la protección de la salud, a la igualdad y a la no discriminación, entre otros muchos, resultan conculcados en este documento, contrario a numerosísimas normas, que consagran los derechos fundamentales de las personas.

Las reacciones a dicho posicionamiento no se hicieron esperar. Entre ellas podemos destacar las siguientes:

- Informe del Comité de Bioética de España.

- $\quad$ Pronunciamiento del Defensor del pueblo.

- Manifestaciones de académicos.

- Pronunciamientos de la sociedad civil.

b) El 25 de marzo de 2020, el Comité de Bioética de España emitía un informe, que subraya que la crisis que afrontamos es una crisis de salud pública y que el bien jurídico que está en juego en la misma no es otro que la vida y salud de muchas personas, especialmente de las más vulnerables. La gravedad de la situación ha dado lugar a la priorización en la asignación de recursos sanitarios, un hecho que, según subraya este documento, no es una novedad por la pandemia sino algo inherente a cualquier sistema de salud. Ante la expansión del coronavirus y el ingente uso de recursos sanitarios en un corto periodo de tiempo, el Comité realiza recomendaciones que tienen que ver, entre otros, con aspectos como la necesidad de adoptar unos criterios equitativos en la asignación de recursos que sean comunes para todos los españoles; la toma de decisiones individualizadas, con participación de los comités de ética asistencial implantados en la mayoría de centros hospitalarios; la no discriminación de las personas mayores; el cuidado de los y las profesionales de la salud; dar prioridad a la asistencia a niños y adolescentes, etc.

Singularmente interesante es su análisis de un término aparecido en muchas de las recomendaciones realizadas, el de "utilidad social", que el Comité tilda de extremadamente ambiguo y éticamente discutible, porque todo ser humano en atención al propio valor ontológico de la dignidad humana, es ya socialmente útil. En este sentido, el informe previene contra la extensión de dicha mentalidad utilitarista o, peor aún, de prejuicios contrarios hacia las personas mayores o con discapacidad. Maximizar unos presuntos intereses o beneficios colectivos, subraya este informe, es incompatible con la primacía de la dignidad humana. Resultaría extremadamente injusto que las personas y colectivos más vulnerables fueran las más perjudicadas por esta crisis; ello atentaría gravemente a los cimientos de una sociedad basada en el imperio de la ley, la igualdad y la justicia. De forma particular hay que atender a consideraciones de equidad (priorizar a los colectivos más vulnerables), que el Comité entiende como el principio que mejor se acomoda a esta crisis. En base a todo lo anterior, el informe concluye que el sistema sanitario español debe basar la toma de decisiones en este momento crítico sobre un modelo mixto que, tomando en consideración el criterio de utilidad social, tenga presentes los principios de equidad y de protección frente a la vulnerabilidad. 
Sentado lo anterior, el Comité critica abiertamente el documento de Recomendaciones éticas para la toma de decisiones en la situación excepcional de crisis por pandemia Covid-19 en las unidades de cuidados intensivos, emitido por SEMICYUC (2020), por entender que algunas de las ideas y recomendaciones que realiza (entre ellas, la referencia a la "supervivencia libre de discapacidad por encima de la supervivencia aislada", o la mención a que los pacientes con deterioro cognitivo, por demencia u otras enfermedades degenerativas, no sean subsidiarios de ventilación mecánica invasiva), resultan claramente incompatibles con la Convención sobre los derechos de las personas con discapacidad, tratado firmado y ratificado por España. En su argumentación traen a colación algunos de sus artículos, ya citados en detalle en otros lugares de este estudio: en concreto el art. 5 (igualdad y no discriminación de las personas con discapacidad); el art. 10 (derecho a la vida de este colectivo, en igualdad de condiciones); el art. 11 (adopción de medidas para garantizar la seguridad y la protección de las personas con discapacidad en situaciones de riesgo, incluidas las emergencias humanitarias); o el art. 25 (derecho a gozar del más alto nivel posible de salud sin discriminación por motivos de discapacidad, exigiendo a los y las profesionales de la salud la prestación de atención de la misma calidad que a las demás personas sobre la base de un consentimiento libre e informado, mediante la sensibilización respecto de los derechos humanos, la dignidad, la autonomía y las necesidades de las personas con discapacidad, mediante la capacitación y la promulgación de normas éticas, e impidiendo la negación discriminatoria de servicios de atención de la salud por motivos de discapacidad).

Todo este articulado avala la principal idea de este pronunciamiento del Comité, que es que la discapacidad de la persona enferma no puede ser nunca por sí misma un motivo que priorice la atención de quienes carecen de discapacidad. Ello contravendría flagrantemente nuestro ordenamiento jurídico, comenzando por la Convención sobre los derechos de las personas con discapacidad, pero sobre todo lesionaría principios éticos esenciales, al clasificar las vidas humanas en diferentes categorías en función de una pretendida y arbitraria utilidad social, asumiendo que la vida de las personas con discapacidad tiene menos calidad y, por tanto, su atención no es tan prioritaria. El reconocimiento y el disfrute de los derechos corresponde, en una sociedad democrática, a todas las personas.

El Comité añade, además, dos consideraciones adicionales. La primera, que en la medida en que las personas con discapacidad, precisamente por dicha circunstancia o por patologías asociadas a la misma, constituyen un grupo especialmente vulnerable frente al coronavirus, lo que podría justificar la discriminación positiva en favor de las mismas en las decisiones asistenciales. En segundo lugar, este órgano llama la atención sobre el retroceso que las personas con discapacidad pueden experimentar, por la suspensión de determinadas terapias imprescindibles para avanzar en su calidad de vida y desarrollo personal. Por ello, instan a que se continúe con dicha atención terapéutica, que la lucha contra el nuevo virus no puede interrumpir.

c) El Defensor del pueblo español también se pronunció en torno a algunas de las implicaciones éticas de la crisis sanitaria del COVID-19. Lo hizo a instancia del delegado de derechos humanos y para la Convención de la ONU del Comité Español de Representantes de Personas con Discapacidad (CERMI). Este comisionado pidió al alto representante de las Cortes Generales para la defensa de los derechos constitucionales que instara al gobierno a garantizar durante la pandemia una atención sanitaria equitativa y sin discriminaciones, que partiera de la premisa fundamental de la protección del derecho humano a la vida sin excepciones, exhortándole a realizar una estrecha vigilancia de recomendaciones emitidas por entidades como las sociedades científicas, que no solo carecen de valor oficial, sino que por su contenido, 
contrario a nuestro ordenamiento jurídico, constituyen una praxis perturbadora capaz de comprometer el bien supremo a la vida de las personas con discapacidad. La administración de los medios sanitarios disponibles, y en general cualquier actuación de los y las profesionales de la salud, debe estar presidida por los mandatos imperativos de derechos humanos de no discriminar ni de tratar desigualmente a las personas, ya presenten o no alguna discapacidad, ni mucho menos clasificar el valor de sus vidas en atención a tal circunstancia.

Ante tales peticiones, el Defensor del pueblo (2020) hizo una llamada a la responsabilidad de poderes públicos, instituciones, entidades sociales y la ciudadanía, instando a respetar y reforzar en esta grave crisis los principios básicos sobre los que se asienta nuestra sociedad democrática, de modo que se garanticen en todo momento la dignidad de las personas, cualquiera sea su condición, y el respeto a los derechos y libertades constitucionales.

En su escrito el Defensor del pueblo subraya, sin entrar en ulteriores consideraciones, su comunicación con el Ministro de Sanidad, en orden a darle traslado de cuestiones que se considera deben ser atendidas con carácter prioritario, así como la necesidad de disponer de un protocolo claro de actuación en todos los servicios de salud, adaptable a la evolución de los acontecimientos.

d) Algunos académicos han aportado sus consideraciones en relación con las recomendaciones emitidas por SEMICYUC. Así lo ha hecho, aunque de forma esquemática y a salvo de un posterior análisis más profundo, Rafael de Asís (2020), quien subraya tres ideas en torno a este texto. La primera de ellas, la falta de cualquier referencia a los derechos humanos o a la dignidad humana. Derivada de la anterior, De Asís observa en dicho discurso discriminaciones y, por ende, eventuales violaciones de nuestro ordenamiento jurídico, como la discriminación por edad o por discapacidad, expresamente formuladas en aquel documento. Finalmente, este autor critica abiertamente el manejo del criterio del valor social de la persona (enferma), hoy superado como contrario al ideal universal de la dignidad humana.

e) Finalmente, hay que hacer referencia al documento emitido sobre esta cuestión por el Ministerio de Sanidad, que en su Informe sobre los aspectos éticos de la pandemia (2020) pretende, entre otros objetivos, garantizar la preservación de los derechos fundamentales, con especial atención a los colectivos más vulnerables. El texto establece que las medidas sanitarias que se adopten estarán presididas por los principios de equidad, no discriminación, solidaridad, justicia, proporcionalidad y transparencia, al tiempo que subraya la absoluta proscripción de criterios fundados en la discriminación por cualquier motivo: excluir a pacientes de cualquier tratamiento resultaría contrario al artículo 14 de la Constitución y comportaría minusvalorar de determinadas vidas humanas frente a otras, lo que ataca los cimientos esenciales de nuestro Estado de Derecho, entre los cuales se encuentra el reconocimiento de la igual dignidad intrínseca de todos los seres humanos. Un argumento que utiliza igualmente para proscribir cualquier discriminación por motivos tales como la discapacidad en cualquiera de sus manifestaciones. 


\section{Conclusiones}

Las personas con discapacidad son un grupo sujeto a una discriminación estructural y sistemática y a profundas desventajas sociales, pese a que los avances en el plano jurídico hacen que sobre el papel gocen de idénticos derechos que el resto de la ciudadanía. La filosofía que subyace este reconocimiento de derechos, patente en muchas normas, y singularmente en la Convención sobre los derechos de las personas con discapacidad, es que la discapacidad es un concepto que evoluciona y que resulta de la interacción entre las personas con deficiencias y las barreras debidas a la actitud y al entorno, que evitan su participación plena y efectiva en la sociedad, en igualdad de condiciones con las demás. De esta idea resultan otras, hoy esenciales a la hora de perfilar sus derechos, como son la importancia de su autonomía e independencia individual, incluida la libertad de tomar sus propias decisiones; el reconocimiento de la diversidad de las personas con discapacidad; o la riqueza que una participación plena de las mismas en todas las facetas de la vida aporta al grueso de la sociedad. Recorrer este camino y conseguir tales logros no ha sido sencillo ni rápido.

Pese al extraordinario avance en la consagración de estos derechos, no resulta fácil garantizar que las personas con discapacidad puedan, en el día a día, ejercerlos plenamente y sin discriminación. Continuamente se encuentran barreras que deben esquivar, y en muchos casos se vulneran abiertamente tales derechos. Dicha problemática se agrava en situaciones de crisis, en las que los poderes públicos operan sobre un diseño de la sociedad que pasa por alto las necesidades de las personas con discapacidad. Ello prueba que la inclusión no es algo automático y esto es lo que ha ocurrido en la crisis del COVID-19 en España.

El enfoque de derechos, basado en el respeto de la dignidad inherente, la autonomía individual, incluida la libertad de tomar las propias decisiones, la independencia, o el respeto al desarrollo de la personalidad de las personas con discapacidad, no está, hoy por hoy, plenamente vigente ni interiorizado por la sociedad; por el contrario, sigue predominando una concepción de este colectivo asentada en la prescindencia o en un modelo médico rehabilitador (CERMI, 2020b). La gestión de la crisis no ha tenido en cuenta las necesidades que una vida independiente y digna requiere para estas personas, en diversos órdenes de cuestiones, y que se han sistematizado en el presente análisis, a partir de informes y numerosa documentación de organizaciones que representan a dicho colectivo.

El no contar con un modelo realmente inclusivo ha tenido consecuencias claramente negativas para las personas con discapacidad, que han sufrido quiebras en sus derechos sanitarios, educativos o relativos al empleo, en mucha mayor medida que el resto de la población. En relación a los primeros, no ha existido en todo este periodo ninguna referencia a sus necesidades, pese a la mayor vulnerabilidad y la especial problemática que este colectivo sufre; además de que muchas personas con discapacidad han visto paralizados sus tratamientos y citas médicas (Silván y Quífez, 2020). Tampoco ha habido previsiones específicas relativas a escolares, estudiantes o trabajadores con discapacidad. El CERMI (2020b: 77) insiste, por ello, en la necesidad de revisar los servicios públicos en clave de inclusión, ya que esta pandemia ha puesto de manifiesto carencias fundamentales a la hora de atender a las personas con discapacidad, mutilando derechos esenciales como la vida o la educación y dejando en precario su atención sanitaria, al no haberse reforzado en absoluto los servicios de soporte, de asistencia o de comunicación, tal y como se recomendó (International Disability Alliance, 2020). Por lo que respecta a la esfera laboral, esencial asimismo para la realización personal y la vida independiente, las personas con discapacidad han sufrido expedientes de 
regulación de empleo temporal (ERTES) en una mayor proporción que el resto de la población, y sus previsiones de recuperación laboral son ciertamente opacas (Silván y Quífez, 2020).

Finalmente, otro aspecto que merece la pena subrayar como consecuencia de la debilidad de un enfoque pleno basado en los derechos, en la igualdad y en la no discriminación de las personas con discapacidad, es la discriminación múltiple y la interseccionalidad, que inevitablemente tienden a agrandarse en situaciones de crisis, y que han perjudicado en mayor medida a las niñas, las mujeres, las personas pobres, migrantes o residentes en el mundo rural (CERMI, 2020b). Ya en los momentos iniciales de la crisis, informes diversos hicieron hincapié en particular, en que todos los planes de preparación y respuesta fueran inclusivos y accesibles para las mujeres con discapacidad (International Disability Alliance, 2020), reclamando específicamente un enfoque de género en este terreno, que resulta imprescindible.

En el otro extremo, algunas circunstancias que han tenido lugar en esta crisis sí que merecen un juicio positivo. En este sentido, es fundamental subrayar que han sido el trabajo y las denuncias de las organizaciones representativas de los derechos de las personas con discapacidad (Confederación Autismo España, CERMI...), las que han motivado rectificaciones del Gobierno, en la medida en que las mismas han estado alerta, desde el principio de la pandemia, posibilitando, por ejemplo, en el periodo de confinamiento, el acceso a la vía pública, con un acompañante, de personas que sufren alteraciones conductuales, como las personas con diagnóstico de espectro autista y conductas disruptivas, que pudieran verse gravadas por la situación de confinamiento.

Las personas con discapacidad y sus familias, y sus organizaciones representativas, han desplegado una actividad importante y eficaz, realizando estudios, recomendaciones, canalizando las denuncias y demandas de las personas con discapacidad y sus familias, interactuando con los poderes públicos y difundiendo todos los datos e información relevante de este colectivo en la presente crisis sanitaria. Con ello han sensibilizado a la opinión pública, de modo que conozca y comprenda las barreras a que las personas con discapacidad se enfrentan y las dificultades para ejercer sus derechos. Su actuación ha sido eficaz y eficiente, y con ella han reivindicado su papel y el rol valioso y fundamental que deben desempeñar en el diálogo civil en todas las cuestiones que afecten a sus representados. Así lo ha constatado también un estudio del CERMI (2020b) que subraya, en este sentido, otros logros fundamentales: su extraordinaria fuerza; su labor múltiple, mitigando la pandemia a través de la prestación de servicios, denunciando cualquier conculcación de derechos, colaborando con los poderes públicos; y el hecho de que todas sus actuaciones se asientan y parten del paradigma de los derechos humanos que guía la Convención, que, si bien no ha calado en el grueso de la sociedad, sí lo ha hecho en las organizaciones representativas de las personas con discapacidad, que reaccionan ante cualquier tentativa de vulnerarlos.

También han sido estas organizaciones las que han criticado las conculcaciones más extremas de tales derechos, provenientes de los pronunciamientos de ciertas sociedades médicas, en torno a la gestión de recursos sanitarios escasos en esta crisis, que anteponían criterios utilitaristas a otros basados en el valor y dignidad de todas las vidas humanas, que cimientan nuestro estado de derecho. Ello sin perjuicio de que otras instancias también hayan participado en el debate, resaltando los aspectos éticos de esta pandemia.

El estudio muestra, en un país desarrollado como España, que usualmente no es escenario de ninguna crisis, cómo ha afectado la pandemia originada por el COVID-19 a las personas con discapacidad, la es- 
casísima atención que han recibido al gestionar la crisis, qué grado de inclusión ha existido y cuál ha sido el comportamiento de los diversos actores -los poderes públicos, las organizaciones representativas de las personas con discapacidad y otra serie de instancias-. En línea con otros trabajos ya mencionados, el estudio subraya la mayor vulnerabilidad de las personas con discapacidad en tiempos de crisis, que no se ve respaldada por una asistencia verdaderamente inclusiva. Existen todavía retos fundamentales pendientes en el terreno de los derechos de las personas con discapacidad, y resulta imprescindible seguir trabajando por avanzar hasta conseguir que la inclusión sea total. También es importante asegurarse de que de la situación de crisis sanitaria extraordinaria no resulte en un retroceso de los derechos que con tanto tiempo y esfuerzo ha conseguido este colectivo.

Por todo ello, y a partir de la experiencia que está suponiendo la crisis del COVID-19, urge que los países firmantes de la Convención de las Naciones Unidas sobre los derechos de las personas con discapacidad elaboren protocolos y adopten medidas para garantizar su protección y seguridad, de aplicación rigurosa e inmediata en la gestión de emergencias. Como señala el CERMI (2020b: 76), la receta no es otra que avanzar sobre la línea de los derechos humanos, a los que considera "la mejor vacuna para mitigar los efectos de esta pandemia en las personas con discapacidad", así como "un escudo infranqueable para proteger su integridad e indemnidad ante las consecuencias sociales, educativas, laborales, sociosanitarias y económicas de esta epidemia". 


\section{Referencias bibliográficas}

de Asís, R. (28 marzo, 2020). Ética y derechos humanos: sobre las recomendaciones éticas para la toma de decisiones en la pandemia COVID-19 [Artículo en un blog]. Recuperado de https://pasocero243055203. com/2020/03/28/etica-y-derechos-humanos-sobre-las-recomendaciones-eticas-para-la-toma-de-decisiones-en-la-pandemia-covid-19/.

Bignal, T. y Gouvier-Seghrouchni, R. (2020). The impact of COVID 19 on disability services in Europe. Bruselas: European Association of Service providers for Persons with Disabilities. Recuperado de https://bit.ly/3ppzPUd.

Burns, N. (2017). "The human right to health: exploring disability, migration and health". Disability and Society, 32(10), pp. 1463-1484.

Comisión Económica para América Latina y el Caribe (CEPAL) (2020). Personas con discapacidad ante la enfermedad por coronavirus (COVID-19) en América Latina y el Caribe: situación y orientaciones. [s. I.]: Naciones Unidas. Recuperado de https://repositorio.cepal.org/bitstream/handle/11362/45491/1/S2000300_es.pdf.

Comité de Bioética de España (2020). Informe del Comité de Bioética de España sobre los aspectos bioéticos de la priorización de recursos sanitarios en el contexto de la crisis del coronavirus. Recuperado de http:// assets.comitedebioetica.es/files/documentacion/Informe\%20CBE-\%20Priorizacion\%20de\%20recursos\%20 sanitarios-coronavirus\%20CBE.pdf.

Comité Español de Representantes de Personas con Discapacidad (CERMI) (2020a): Las personas con discapacidad y sus familias ante la crisis sanitaria del coronavirus: prontuario de necesidades en la gestión inmediata de la pandemia. Madrid: Comité Español de Representantes de Personas con Discapacidad. Recuperado de https://www.cermi.es/sites/default/files/docs/novedades/Documento\%20Discapacidad\%20y\%20coronavirus $\% 20-\% 20$ recomendaciones.pdf.

Comité Español de Representantes de Personas con Discapacidad (CERMI) (2020b). El impacto de la pandemia del Coronavirus en los derechos humanos de las personas con discapacidad en España. Informe de urgencia del CERMI Estatal. Madrid: Comité Español de Representantes de Personas con Discapacidad. Recuperado de https://bit.ly/3kuFi8J.

Confederación Autismo España (18 marzo, 2020). ¿Qué puede ocurrirle a la persona con trastorno del espectro del autismo que se ve afectada por las medidas establecidas en el RD463/2020, de 14 de marzo? [Noticia en web]. Recuperado de http://www.autismo.org.es/actualidad/articulo/que-puede-ocurrirle-la-persona-contrastorno-del-espectro-del-autismo-que-se-ve.

Confederación Autismo España (2020): Documento de posicionamiento. Derecho a la salud de las personas con trastorno del espectro del autismo, en la situación de crisis sanitaria por COVID-19. Madrid: Confederación Autismo España. Recuperado de https://estadoalarmatea.org/wp-content/uploads/2020/04/documento_de_posicionamiento_autismo_espana_derecho_a_la_salud.pdf.

Defensor del Pueblo (2020). Documento del 27/3/2020, emitido en relación al expediente $n^{\circ} 20004746$, instado por Delegado de Derechos Humanos y para la Convención de la ONU, Comité Español de Representantes de Personas con Discapacidad (CERMI).

España. Constitución Española. Boletín Oficial del Estado, 29 de diciembre de 1978, núm. 311, pp. $29313-29424$. 
España. Instrucción de 19 de marzo de 2020, del Ministerio de Sanidad, por la que se establecen criterios interpretativos para la gestión de la situación de crisis sanitaria ocasionada por el COVID-19. Boletín Oficial del Estado, 20 de marzo de 2020, núm. 76, pp. 26311-26312.

España. Instrumento de ratificación de 29 de abril de 1980, de la Carta Social Europea, hecha en Turín de 18 de octubre de 1961. Boletín Oficial del Estado, 26 de junio de 1980, núm. 153, pp. 14533-14540.

España. Instrumento de ratificación del Protocolo Facultativo a la Convención sobre los derechos de las personas con discapacidad, hecho en Nueva York el 13 de diciembre de 2006. Boletín Oficial del Estado, 21 de abril de 2008, núm. 96, pp. 20648-20659.

España. Ley 14/1986, de 25 de abril, General de Sanidad. Boletín Oficial del Estado, 29 de abril de 1986, núm. 102, pp. 15207-15224.

España. Ley 26/2011, de 1 de agosto, de adaptación normativa a la Convención Internacional sobre los Derechos de las Personas con Discapacidad. Boletín Oficial del Estado, 2 de agosto de 2011, núm. 184, pp. 8747887494.

España. Real Decreto 1276/2011, de 16 de septiembre, de adaptación normativa a la Convención Internacional sobre los derechos de las personas con discapacidad. Boletín Oficial del Estado, 17 de septiembre de 2011, núm. 224, pp. 98872-98879.

España. Real Decreto 463/2020, de 14 de marzo, por el que se declara el estado de alarma para la gestión de la situación de crisis sanitaria ocasionada por el COVID-19. Boletín Oficial del Estado, 14 de marzo de 2020, núm. 67 , pp. 25390-25400.

España. Real Decreto 465/2020, por el que se modifica el Real Decreto 463/2020, de 14 de marzo, por el que se declara el estado de alarma para la gestión de la situación de crisis sanitaria ocasionada por el COVID-19. Boletín Oficial del Estado, 18 de marzo de 2020, núm. 73, pp. 25944-25945.

España. Real Decreto Legislativo 1/2013, de 29 de noviembre, por el que se aprueba el Texto Refundido de la Ley General de derechos de las personas con discapacidad y de su inclusión social. Boletín Oficial del Estado, 3 de diciembre de 2013, núm. 289, pp. 95635-95673.

España. Real Decreto-Ley 8/2020, de medidas urgentes extraordinarias para hacer frente al impacto económico y social del COVID-19. Boletín Oficial del Estado, 18 de marzo de 2020, núm. 73, pp. 25853-25898.

Handicap International Federation (2015). Disability in humanitarian context. Views from affected people and field organisations. [Lyon]: Handicap International Federation. Recuperado de https://d3n8a8pro7vhmx.cloudfront. net/handicapinternational/pages/1479/attachments/original/1443729529/_Handicap_International_Disability_in_humanitarian_context.pdf?1443729529=.

Hernández, J. y Millán, J. M. (2015). "Las personas con discapacidad en España: inserción laboral y crisis económica". Revista Española de Discapacidad, 3(1), pp. 29-56. DOI: http://dx.doi.org/10.5569/2340-5104.03.01.02.

International Disability Alliance (IDA) (2020). Toward a disability-inclusive COVID-19 response: 10 recommendations from the International Disability Alliance. Recuperado de https://www.internationaldisabilityalliance.org/ sites/default/files/ida_recommendations_for_disability-inclusive_covid19_response_final.pdf.

Ministerio de Sanidad de España (2020a). Informe del Ministerio de Sanidad sobre los aspectos éticos en situaciones de pandemia: EI SARS-CoV-2. Recuperado de https://www.mscbs.gob.es/profesionales/saludPublica/ ccayes/alertasActual/nCov-China/documentos/AspectosEticos_en_situaciones_de_pandemia.pdf.

Ministerio de Sanidad de España (2020b). Información Coronavirus. Recuperado de https://www.mscbs.gob.es/. 
Mitchell, D. y Karr, V. (2014). Crises, conflict and disability: Ensuring equality. Abingdon: Routledge.

ONU (2020a). COVID-19: ¿Quién protege a las personas con discapacidad?, alerta experta de la ONU [Noticia en web]. Recuperado de https://www.ohchr.org/SP/NewsEvents/Pages/DisplayNews.aspx?NewsID=25725\&LangID=S.

ONU (2020b). Declaración conjunta representantes ONU: personas con discapacidad y COVID-19. Recuperado de https://www.indh.cl/declaracion-conjunta-representantes-onu-personas-con-discapacidad-y-covid-19.

ONU (2020c). Declaración del Comité de Derechos del Niño de las Naciones Unidas. Recuperado de https://tbinternet.ohchr.org/Treaties/CRC/Shared\%20Documents/1_Global/INT_CRC_STA_9095_E.pdf.

ONU (2020d). Mensaje del Secretario General de la ONU con motivo del Día Mundial de Concienciación sobre el Autismo. Recuperado de https://www.un.org/es/observances/autism-day.

Organización Mundial de la Salud (OMS) (2020a). Alocución de apertura del Director General de la OMS en la rueda de prensa sobre la COVID-19. Recuperado de https://www.who.int/es/dg/speeches/detail/who-directorgeneral-s-opening-remarks-at-the-media-briefing-on-covid-19---11-march-2020.

Organización Mundial de la Salud (OMS) (2020b). Disability considerations during the COVID-19 outbreak. Recuperado de https://www.who.int/publications/i/item/WHO-2019-nCoV-Disability-2020-1.

Rotarou, E. S. y Sakellariou, D. (2017). “Access to health care in an age of austerity: disabled people's unmet needs in Greece". Critical Public Health, 1, pp. 1-13.

Silván, C. y Quífez, L. (2020). Efectos y consecuencias de la crisis de la COVID-19 entre las personas con discapacidad. Madrid: Fundación Once. Recuperado de https://bit.ly/3neGezM.

Sociedad Española de Medicina Intensiva, Crítica y Unidades Coronarias (SEMICYUC) (2020). Recomendaciones éticas para la toma de decisiones en la situación excepcional de crisis por pandemia Covid-19 en las unidades de cuidados intensivos. Recuperado de https://semicyuc.org/wp-content/uploads/2020/03/\%C3\%89tica_SEMICYUC-COVID-19.pdf.

Unión Europea (2010). Estrategia Europea sobre Discapacidad 2010-2020: un compromiso renovado para una Europa sin barreras. Recuperado de https://eur-lex.europa.eu/legal-content/ES/TXT/PDF/?uri=CELEX:52010 DC0636\&from=ES.

Unión Europea (2020). Presidency report on the state of play of EU-coordination in response to the COVID-19 pandemic. Recuperado de https://data.consilium.europa.eu/doc/document/ST-12559-2020-INIT/en/pdf. 